\title{
FACTORS AFFECTING THE SUCCESS OF LOGISTICS ENTERPRISES IN VIETNAM
}

\author{
Phung Thi Thanh ${ }^{1}$, Nguyen Thi Huyen Tran ${ }^{2}$ Tran Thi Phuong Thuy ${ }^{3}$ \\ ${ }^{1}$ Foreign Trade University Hochiminh city campus, 15 D5 Street 25 Ward Binh Thanh District, \\ HochiminhCity, 084, Vietnam, thanhphung.ftu@gmail.com, (028.35127258) \\ ${ }^{2}$ Foreign Trade University Hochiminh city campus, 15 D5 Street 25 Ward Binh Thanh District, \\ HochiminhCity, 084, Vietnam, nguyenthihuyentran.cs2@ftu.edu.vn, (0909828275) \\ ${ }^{3}$ Foreign Trade University Hochiminh city campus, 15 D5 Street 25 Ward Binh Thanh District, \\ HochiminhCity, 084, Vietnam tranthiphuongthuy.cs2@ftu.edu.vn, (0908934282)
}

\begin{abstract}
Logistics has become quick developing and important industry which contributes large percentage in Vietnam's GDP. However, with about 1,300 firms operating in this industry, only few firms have been successful in activity, the others have been facing mangy difficulties. The reason why this circumstance occurred was raised up encourage authors to conduct this research. Buy using FsQCA, some interesting results were found. Most important finding was that there consist different viewpoints between two groups of companies (leading companies and the others). As for all successful businesses in the industry, all factors affect the company's business results if they interact with each other and are combined to create a quite large level of influence for each logistics business. For other logistics businesses, their concern is not all of the seven elements. Two different perspectives are given when firms assess the factors that influence success. This implies somewhat conclude to success or unsuccess of logistics companies.
\end{abstract}

\section{Keywords}

Logistics, success, factors, management

\section{JEL Classification}

C52

DOI: https://doi.org/10.14311/bit.2019.01.04

Editorial information: journal Business \& IT, ISSN 2570-7434, CreativeCommons license (c) (i) published by CTU in Prague, 2019, http://bit.fsv.cvut.cz/ 


\section{Introduction}

Globalization is a trend that has been strongly growing all over the world. This not only creates favorable conditions for countries to accelerate the import and export of goods and their trade with the rest of the world, but also smoothens the flow of goods, creating a broad market for fair competition on trade and investment. Along with this increasingly integrated process, logistics is increasingly focused by its importance.

In recent years, especially after Vietnam's integration into the world, logistics has become an important factor contributing to the growth of the Vietnamese economy. Historically, the distribution of goods, exchanges of trade between regions in the country and with foreign countries have always been the essential activity of the national economy. If these activities are smooth and effective, it will greatly contribute to the development of the manufacturing industry. If these activities are stopped, it will negatively affect the whole production and life. In addition, for Vietnam, a country with strong and highly dependence on natural resources, logistics plays a more important role. Each geographic region has different terrain features, different mineral resources and different modes of work and practice, thus the distribution of industries, industrial parks, and economic centers must be in line with specific and general conditions in order to maximize the resources.

In order to meet the increasing demand of the market, there are many positive changes of Vietnamese logistics service with the growing number of enterprises operating in this field. Some companies have found the right path to success and establish strong position in the logistics service market. In addition, there are small businesses, focusing on very small work areas, not creating more value so they cannot compete in domestic market. Therefore, the service of domestic logistics companies only meets about $25 \%$ of the actual demand. In the context of increasing import and export activities of Vietnam, exponentially expanding domestic trade and the increasing demand for logistics services, this issue needs to be paid special attention to restrict the loss of domestic enterprises on the domestic market.

In order to help businesses grow and achieve success in the logistics industry, it is necessary first to identify the factors affecting the success of the logistics companies, thereby evaluating and promoting the strengths, improving the weaknesses in the operation of logistics enterprises. Logistics companies who want to succeed in this field should identify the key factors affecting their business results.

In fact, there is very little empirical researches in Vietnam on this issue. Previous studies mainly looked at business success in qualitative aspects. Thus, the authors chooses to study the topic "Factors affecting the success of logistics enterprises in Vietnam" with the desire to point out the factors affecting the success of logistics enterprise, so that they have the basis to strongly develop their company. The authors focus on the factors affecting the success of logistics enterprises in Vietnam. These successful enterprises are among the 20 most successful logistics enterprises in 2015 according to the Vietnam Association of Logistics Services (VLA). In addition, the study also examines logistics enterprises in the industry to compare the impact of these factors.

The study focuses on the period from 2007 to present for a number of reasons. Firstly, in 2007, Vietnam Freight Forwarders Association (VIFFAS) was renamed Vietnam Logistics Service Enterprise (VLA). This is a big turning point in the logistics industry in Vietnam, showing that Vietnam's logistics is gradually integrating with global trend. Secondly, the logistics industry has made great strides and there is no sign of slowing down to this point. Thus, it can be said that the period 2007 - now is a period of strong development of logistics services, so research in this period will bring practical value for research. 
The study was conducted through 3 main steps: The first step: secondary and primary data collection of the 20 most successful logistics companies and other logistics enterprises in Vietnam; the second step: analysis of collected data; the last step: compare the results between two groups of enterprises.

Regarding secondary data collection phase of the 20 most successful logistics enterprises in Vietnam, the authors collected data from the website of the Vietnam Association of Logistics Services (VLA). In addition, the authors also collected data from other businesses operating in this field. Regarding the analysis of primary data, the authors used fsQCA 2.0 to draw conclusions about the factors that really affect the success of the logistics businesses.

\section{Literature review}

In Vietnam, logistics is often understood as "logistics", however, the word itself does not explain and embody the full meaning of the term logistics. Thus, the term was used in the original text of Article 233 of the Commercial Law 2005, which states: "Logistics is a commercial activity whereby a business entity conducts one or more works including delivery, transportation, warehousing, storage, customs clearance, other paperwork, customer consultation, packaging, marking, delivery or other related services under the agreement with customers for remuneration". It can be seen that this concept is no longer appropriate to the reality because the role of logistics is increasingly expanding and not just the delivery of goods or customs clearance. Moreover, this service has developed to a new level, creating more value for the economy, integrating more and more deeply into the operation of enterprises, from the input of raw materials to the production and launching the goods into the market.

With the logistics concepts mentioned above, it can be seen that logistics is a concept that can be understood in many angles. In broad terms, it is possible to understand that logistics begins with the optimization of the production cycle, not only with the flow of raw materials and fuels for the production, production of goods, but also with the act to bring the goods to the market, distribute to the end consumers. To do this, the logistics service provider must meet certain requirements in terms of expertise and resources, so that they can provide such a package of services. In the narrow sense, logistics is understood to be the same as freight forwarding, including many transport elements in the service delivery.

Within the research scope of this study, logistics activity is mainly considered as the process of organizing and managing the flow of goods as well as other activities related to the import and export process of goods to optimize in terms of time and bring high economic efficiency.

\section{Concept of logistics service providers}

According to the definition of logistics business of the Business Dictionary, logistics service providers are understood as companies providing services that manage the flow of goods and materials from the beginning to the last point. These companies also provide transportation, packing and warehousing services.

Brian Bass defines the logistics business based on the jobs, functions and tasks that the company will undertake. According to him, the logistics business is the organization that provides logistics solutions to other companies. These companies will specialize in the transportation, distribution, packaging, storage and storage of merchandise.

Article 234 of the Commercial Law 2005 defines: "Traders engaging in the business of providing logistics services are qualified enterprises providing logistics services in accordance with the law". These conditions are listed in the Decree No. 140/2007/ND-CP stipulating the Commercial Law on the conditions for trading in logistics services and the limitation of liability for traders providing logistic 
services. Article 3 of this Decree states that "traders providing logistics services are traders providing logistics services to customers by themselves or by subcontractors performing one or more stages of that service". Traders can be understood by the definition of Commercial Law 2005 as "legally established economic organizations that operate independently and regularly and have business registration".

Within the scope of this paper, logistics enterprises are understood as such enterprises that organize and provide transportation services for raw materials, materials and goods, strategies for control and cost optimization during transportation as well as other related processes.

\section{The concept of success}

Success is a difficult concept to define because each person has a unique perspective on success. Some people define success based on financial criteria, some define success based on the material and spiritual results they achieve. So far, there is no definite definition of business success.

The Merriam-Webster Dictionary defines success as "achieving wealth, respect or fame in reality. This is a defining paradigm of individual success rather than the success of the business".

Myers M. Dialectic (1994), in his research "A theoretical framework for the implementation of information systems", states that "success can be achieved when the information system is perceived as success by the related people". Success can be defined by the external category, from the perspective of people around, not from the perspective of each person.

Wilson M, Howcroft D (2002) in his research "Re-conceptualizing failure: social shaping meets IS research", defines "success is the survival of a company". This is a fairly brief but comprehensive concept. In order to scale up its operations and be more successful, the first thing is that a company must survive in a competitive environment. This existence can be considered as the initial success of the business.

DeLone W, McLean E (2004) in the study "Measuring e-commerce success: applying the DeLone and McLean information systems success model" states that "Net profit represents the most basic category of success".

In general, success is an intangible concept that is difficult to quantify. And there is no academic definition of business success. Understanding success depends on the views of individuals and groups. Within the scope of the research, the authors understand that success is the achievement of good business results, high performance and is evaluated based on financial manifestations such as turnover, profit and welfare, employees' benefit and the position of the business in comparison with other businesses in the same field.

\section{Methodology}

The study was conducted in two phases, including preliminary research and formal research. The authors made preliminary research on the topic using qualitative methods to identify problem and research objectives. The authors have synthesized the basic theoretical foundations and available studies to underpin the subject.

The formal quantitative study was conducted by direct interview and questionnaire with employees in logistics companies. In addition, online survey was also sent to employees in the subject group. The survey was designed on a scale from 1 to 7 , with 1 meaning being completely disagreeable and 7 meaning being completely agreeable. The authors selected the survey of 20 most successful enterprises in 2015 according to the Vietnam Association of Logistics Services (VLA) to conduct the survey. In addition, the authors also conducted a survey of any business to compare the two groups. 
For each business, the authors conducted a survey of one or two objects, from the results obtained, the authors used the average to obtain the final result from each company and use it for research.

From the data collected, the authors used Microsoft Excel 2013 software to analyze descriptive statistics for some of the basic characteristics of the dataset. Data were then used for analysis through the Truth Table algorithm and fuzzy sets analysis using the fsQCA 2.0 tool to identify the factors affecting the success of the logistics enterprises in Vietnam.

Fuzzy-set The Qualitative Comparative Analysis (fsQCA) is an analytical method of qualitative and quantitative analysis that is not based on statistical theory but on the basis of fuzzy sets. This method has many advantages over conventional regression analysis. FsQCA evaluates the degree of "need" and "sufficiency" of an influential factor based on hypothesis rather than simply analyzing the influence of independent and dependent variables (Fiss, 2007). While linear regression analysis requires large sample sizes and is often used for management studies (Rihoux, 2006; Woodside et al., 2012), fsQCA fits into smaller sample studies. The authors chose to use this analytical method to obtain the most accurate results on the impact of the influencing factors and the relationship between them. The analysis of the results will help to provide a general overview of the success of logistics enterprises and the factors that affect this success.

For fsQCA, data collected from Likert scale 1 to 7 were converted to fsQCA data from 0 to 1 (Ragin, 2008). The authors used the Calibrate function to convert fsQCA's magnitude scale to scale in the data collection process and will use this algorithm to exploit and provide key data for the study. Truth Table is a data matrix consisting of $2 \mathrm{k}$ rows, where $\mathrm{k}$ is the number of factors of the model and each row represents a unique combination of research factors. After using this algorithm, the Truth Table will be filtered based on the frequency that shows the number of occurrences of the factor in the rows of the Truth Table and the consistency that indicates the relevance. The solutions that algorithms give to the results/phenomena needed to study (Ragin, 2008). According to Ragin, 2008; Leischnig, Henneberg and Thornton, 2014, when analyzing the condition of a phenomenon, the threshold of the consistency coefficient should be at least 0.8 and greater than 0.9 . In this paper, the authors analyzed the results of the Truth Table algorithm based on the fsQCA study by Ragin (2008), Emmenegger (2011), Leischnig, Henneberg and Thornton (2014) The frequency is 1 , the consistency factor is greater than 0.9 .

The solution to the problem of the research paper will be given after Truth Table filtering and in conjunction with the analytical algorithm. These solutions are produced with consistent coefficients and explanatory ratios, or raw coverage that draw conclusions about the impact of the factors and assess the level of their importance. Net coverage is an indicator of the level of explanation of each solution to the outcome/phenomenon and the importance of each solution (Ragin, 2008). The scaling factor should be at least 0.4 , so the solutions offered are reliable and acceptable (Emmenegger, 2011). In the paper, the authors selected a net cover greater than 0.4 .

The survey to collect data is the official survey designed and adjusted by the authors after direct interview and consulted by some logistics experts and interviewees in some enterprises. The data were collected by direct survey through the paper survey of employees in the list of 20 most successful logistics enterprises in 2015 which the author selected and any logistics enterprises. In addition, the authors used email communications to send online surveys to the respondents. The data collection process was conducted by the authors in September and October 2017.

The survey consisted of two parts. The first is the assessment, which is the most important part of the survey. The 53 questionnaires were used for the respondents to evaluate the importance of variables in the research model based on a 7-point scale. The second part is the personal information of the respondents with two questions to collect personal information of the subject. 
After compiling the list of the 20 most successful logistics enterprises in Vietnam in 2015 and the list of other randomly surveyed logistics businesses, the authors sent the survey to 150 companies in two ways: go directly to the company to interview through questionnaire and receive survey results; send surveys via email to corporate email. The authors chose to survey two respondents in each company to make the most accurate assessment. After collecting data and summarizing the results, 82 questionnaires were completed in both online and paper forms. However, 13 questionnaires were excluded, of which 6 were rejected because the name of the company the respondents work was not identified, 7 questionnaires were rejected because the respondents does not work in logistics companies. The remaining sample size is 69 , consisting of 30 samples from the successful business group and 39 samples from the other group. This sample size can be analyzed by fsQCA software (Leischnig, Henneberg and Thornton, 2014).

\section{Results}

The authors used Microsoft Excel 2013 software to process and analyze data. Each of the variables evaluated by the authors was based on two indices: mean value and dispersion or standard deviation. This standard deviation value indicates the degree of variability of the data.

Regarding the quality of service, the average score is 5.71 . Observed variables range from 4.97 to 6.3. The variable measuring "The large number of specialized containers and cargo handling equipment such as bar code scanners, weighing scales, forklifts, etc." (DV3) has the lowest average value (4.97) and dispersion is fairly high, reaching 1.7. The variable measuring "The commitment of the company to ensure its customer service quality" (DV7) has the highest average value (6.3) and low dispersion (1.31). This shows that the business commitment of the service they provide affects the quality of the service but not so much.

Regarding the customer relationship management, the average score for this criterion is 5.72 . This is the highest score among the customer-related factors. Observed variables ranged from 5.27 to 6.17. The variable measuring "the company must use customer care management software" (QH5) has the lowest average value (5.27) and the dispersion of 1.21. The variable measuring "Staff must always listen to customer feedback and answer" (QH2) has the highest average value (6.17) and the dispersion is quite low (1.16). It can be concluded that the use of customer management software does not interfere with the management of the relationship between the company and the customer. The listening to new customers really affect this relationship.

In terms of customer retention, the average score is 5.59 and the median values range from 5.13 to 6.1. The variable measuring "Companies have to invest heavily in communication activities to reach customers" (DT1) has the lowest value (5.13) and the dispersion reaches 1.31. The variable measuring "Companies must establish good relationships with customers from the first transaction" (DT3) has the highest average value (6.1) and the lowest dispersion (1.16). Communication is not the biggest factor affecting the relationship with customers of the enterprises.

Regarding human resources, the average score for all sub-variables is 5.62. The mean value of the variables runs from 5.0 to 5.93 . The variable measuring "Our staff's payroll ratio is higher than the rival firm for the same position" (NL5) has the lowest average value (5.0) and low dispersion (1.13). The variable measuring "When choosing an employee for a new position, we choose based on the individual's learning and development potential when working in a company" (NL2) has highest average value of 5.93 and the lowest dispersion (1.09). It can be seen that the salary of the employees is one of interest of respondents but not the biggest concern.

As for the corporate culture, the average value of this component is 5.93. The average value ranges from 5.80 to 6.03 . The variable measuring "Company always allows employees to participate in public 
discussions" (VH1) has the lowest average value (5.80) and the relatively low dispersion (1.05). The variable "Company always facilitates employees to connect and work together" (VH3) has the highest average value (6.03) and the dispersion of 1.11. This can be seen that the internal environment of a business is the most important variable in this component.

Regarding the structure of the company, the average value is 5.9 and range from 5.63 to 6.33 . The variable "Company must be flexible, adaptable to continuously changing environment" (CC1) has the lowest average value (5.63) and the dispersion is 1.25. The variable "Company should assign tasks that suit each employee to maximize their capacity" (CC2) has the highest average value (6.33) and the lowest dispersion (0.91).

Regarding the leadership, the mean value is quite high and it is also the highest out of the four components measuring the influence of the internal factors of the enterprise (6.07). The variable "The leader must act as a facilitator, recognizing the individual's differences to maximize their potential" (LD1) has the highest mean value (6.13). The variable "The leader must set the right expectation for each employee, and reward incentives when the employee delivers the expected result" (LD2) has the lowest average value (6.0). The dispersion of variables in this component is not much different (from 1.13 to 1.18$)$.

Regarding components related to the business environment, the political component has an average value of 5.37 and a dispersion of 1.17. The average value of economics is 5.57 and the dispersion is 1.15. The technology component has an average value of 5.4 and a dispersion of 1.2. The labor component has an average value of 5.30 and a dispersion of 1.16. The competition component has an average value of 5.90 and a dispersion of 1.33. It can be seen that the factors of business environment are considerable interest as it is a condition for the business process to be better. In particular, for successful businesses, they focus more on the level of competition in the industry than are controlled and governed by the government such as politics, economics, policy relating to technology and workforce.

In general, the components have relatively high average value, which can prove that the components have a certain degree of influence on the success of the logistics business. To determine and ensure that components that affect this success, fsQCA's fuzzy set analysis method will be used.

For successful or unsuccessful businesses, the impact of the business environment on each business is the same because they work together and compete in the same market, with the same level of incentives for all businesses. Therefore, the authors only analyzed and evaluated the impact of the factors related to the customer and the internal factors of the business to determine the extent of their impacts on this success. The authors used the Truth Table algorithm for analysis as follows:

Step 1: The three factors of customer and four factors of internal business are assigned to new variable, the value of which is calculated by the average math addition of the component variables in each factor;

Step 2: The authors selected three benchmarks: a full membership point with a fuzzy score of 7, a cross point with a fuzzy point of 4 , full nonmember ship with a fuzzy point of 1 . The authors converted the magnitude scale 7 (from 1 to 7 ) into a scale of fsQCA (0.0 to 1.0) with the Calibrate function to run the Truth Table.

Step 3: The Truth Table algorithm was used to analyze the effect on the variable "success", seven variables are quality of service, customer relationship management, customer retention, human resources, corporate culture, company structure and leadership. 
After filtering the Truth Table by frequency with 1 and consistency $>0.9$, the results are shown in the Table 1 below:

Table 1: Impact assessment of factors affecting the success of logistics enterprises (top 20)

\begin{tabular}{|c|c|c|c|}
\hline Factor & Solution 1 & Solution 2 & Solution 3 \\
\hline Quality of service & $\square$ & 回 & ? \\
\hline Customer relationship management & ?] & $\square$ & ? \\
\hline Customer retention & ? & $\square$ & ? \\
\hline Human resources & ? & ? & ? \\
\hline Corporate culture & ?] & ? & 目 \\
\hline Company structure & $\square$ & 圆 & 圆 \\
\hline Leadership & $\square$ & 回 & 回 \\
\hline Raw Coverage & 0.1353 & 0.1939 & 0.8512 \\
\hline Unique Coverage & 0.0193 & 0.0081 & 0.659 \\
\hline Consistency & 0.9691 & 1.00 & 0.936 \\
\hline Solution Coverage & \multicolumn{3}{|c|}{0.8788} \\
\hline Solution Consistency & \multicolumn{3}{|c|}{0.9336} \\
\hline
\end{tabular}

Note: 目: the appearance of factor

$\square$ : the absence of factor

From the Table 1, with 7 variables included in the analysis, three solutions were proposed. However, only one solution affecting the success of the logistics business in Vietnam is the third option, satisfying the condition: "the net coverage of the solution is greater than 0.4 ". With the appearance of all seven factors, the net coverage of the solution is very high, reaching 0.8512 , which proves that the solution explains $85.12 \%$ of the components affecting the success of enterprises. Only $14.88 \%$ of other factors have impact but have not been included in the model. The consistency coefficient of the solution was also very high, reaching 0.936 , indicating that this solution was correct in $93.6 \%$ of cases and had an effect on the success of the logistics enterprise (Ragin, 2008).

Thus, looking at all three solutions, the two factors of human resources and corporate culture are present in all three solutions. It can be asserted that these two factors always have a moderate impact on the success of the business. Coverage or net coverage of all three solutions was 0.8788 and explained $87.88 \%$ whether internal and customer-related factors really affect the success of the business or not. The consistency of the solution was 0.9336 , ranging from 0.8 to 0.9 , which should be accepted and validated in practice.

From the results of the analysis of Solution 1 and 2, it can be seen that the three elements of company structure, leadership and service quality are stronger than the two factors of customer relationship management and customer retention. The level of explanation for the solution increases with the presence of three factors in the second solution in comparison with Solution 1. However, the importance of these three factors is not too great and the business does not need to pay too much attention. Instead, they should concentrate on developing other factors.

In comparison between Solution 3 and Solution 1, the presence of three factors: corporate structure, leadership and service quality in Solution 3 resulted in a net increase of over $71 \%$ over Solution 1 (from 0.1353 to 0.8512 ), the level of explanation of the solution to the success of the 
business increased quite considerably. This proves that these three factors have great influence on the success of the business. If the enterprises do not have the resources to invest in all the elements, they should focus on these three factors first.

In comparison between Solution 3 and 2, the presence of two factors: customer relationship management and customer retention in Solution 3 resulted in an explanation level of more than $63 \%$ over Solution 2 (from 0.1939 to 0.8512 ). This proves that these two factors also play big role in the success of the business. These are the aspects that businesses should invest heavily in developing larger companies in the market.

It can be said that the impact level of the quality of service provided by enterprises, the structure of the organization as well as the leadership are greater than the rest. Businesses should focus on and prioritize these three factors first, then customer relationship management and customer retention. The impact of human resources and the cultural environment of the company do not account for large percentage so businesses do not need to focus too much on these factors.

Table 2: Impact assessment of factors affecting the success of logistics enterprises (the other group)

\begin{tabular}{|c|c|c|c|}
\hline Factor & Solution 1 & Solution 2 & Solution 3 \\
\hline Quality of service & ? & ? & ?? \\
\hline $\begin{array}{ll}\text { Customer } & \text { relationship } \\
\text { management } & \end{array}$ & $\square$ & 囼 & ? \\
\hline Customer retention & $\square$ & ? & \\
\hline Human resources & & & ? \\
\hline Corporate culture & ? & ? & ] \\
\hline Company structure & ? & ? & ? \\
\hline Leadership & ? & ? & ? \\
\hline Raw Coverage & 0.3012 & 0.8825 & 0.8969 \\
\hline Unique Coverage & 0.0188 & 0.0056 & 0.0216 \\
\hline Consistency & 0.9307 & 0.8939 & 0.8869 \\
\hline Solution Coverage & 0.929 & & \\
\hline Solution Consistency & 0.8687 & & \\
\hline
\end{tabular}

From the Table 2, there are 3 solutions, of which only Solution 2 and 3 are of high practical significance, satisfying the condition of pure coverage of 0.4 . These two solutions are reliable in practice (Emmenegger, 2011).

Solution 1 including service quality, corporate culture, corporate structure and leadership has low net coverage and low reliability because net coverage of this solution is $0.3012<0.4$. The four factors that appear only account for $30.12 \%$ of the success of the logistics enterprises. This is not a combination of reliable factors in practice.

Solution 2 includes the following elements: service quality, customer relationship management, customer retention, corporate culture, corporate structure, leadership. This solution has a high net coverage and accounts for $88.25 \%$ of factors affecting the success of the enterprises. The consistency coefficient of this solution is 0.8939 . The common consistency factor should reach a minimum of 0.8 and preferably greater than 0.9 when analyzing the condition and probability of a phenomenon or event (Ragin, 2008). Although the consistency coefficient is less than 0.9 , this solution is still acceptable and still relevant in explaining the success of the enterprises. 
Solution 3 includes the following elements: service quality, customer relationship management, human resources, corporate culture, corporate structure, leadership and customer retention. Net coverage of the solution is higher than any of the three solutions, reaching 0.8969 , which accounted for $89.69 \%$ of the constituents of the enterprises' success. $11.31 \%$ of other factors also have impact on this success but have not been included in the model for analysis. Like Solution 2, although the consistency of Solution 3 is less than 0.9 , it is still acceptable because it stays between 0.8 and 0.9 (Ragin, 2008). This solution has an explanation level of $88.69 \%$ in practice.

All three solutions have four common factors, including quality of service, corporate culture, corporate structure and leadership. This proves that these 4 factors have strong impact on the success of the enterprises but not high. The combination of these four factors is not so tight that it can have big impact on every company. The net coverage of the solution is 0.929 , which could confirm that the combination of these three solutions account for $92.9 \%$ of the company's success. The solution consistency is $\mathbf{0 . 8 6 8 7}$, indicating that this combination is appropriate in practice.

By comparing Solution 1 and 2, it can be seen that the presence of two factors (customer retention factors and customer relationship management) in Solution 2 results in a significant increase in net coverage of the solution, at $58 \%$ (from 0.3012 up to 0.8825 ). This proves that these two factors play a very important role in the success of the business, higher than the impact of a combination of four factors (service quality, corporate culture, corporate structure and leadership). These two factors have very high levels of resonance and are interrelated, interacting and impacting the success of the enterprises.

In comparison between Solution 1 and 3, in Solution 3 there are 6 factors affecting success, in addition to the four factors identified in Solution 1, there is also customer relationship management and human resources. With the emergence of these two factors, the net coverage of the solution increased (59.57\%), more than the increase in solution 2 (from 0.3012 to 0.8969 ). Thus, it can be argued that the management of the customer relationship and the skilled workforce of each enterprise have great impact on the business performance and determine the level and speed the development of such company.

Both Solution 2 and 3 are acceptable because they satisfy the condition of pure coverage. However, the variables that affect the success of the enterprises in the two solutions also change and that change leads to the increase of pure coverage. Solution 3 has the appearance of the human resources factor and does not have the appearance of the customer retention factor, while Solution 2 has the appearance of this factor but does not have the human resources variable. The net coverage of Solution 3 is greater than Solution 2 but not significant $(0.8969>0.8825)$. It can be argued that the human factor has a stronger impact on customer retention and resonance with customer relationship management. The combination of customer relationship management and customer retention have impact more than $58 \%$ on success, while customer relationship management and human resources affect $59 \%$.

Thus, in addition to the four fundamental factors affecting the success of the enterprises, companies need to pay attention on the management of customer relationships, take appropriate measures to maintain relationships with customers as well as build high quality human resources. However, if the enterprises do not have sufficient resources, it is possible to temporarily abandon the relationship with the customer but still focus on the remaining factors. Enterprises should prioritize the development of the company's human resources rather than maintaining relationships with customers. 


\section{Conclusion and discussion}

This study is aimed at identifying factors affecting the success of logistics enterprises in Vietnam. The authors developed a scale of components that affect this success based on the studies by Alan C. Maltz (2000) and Dynamic Performance Multiplier Model (DMP) by Maltz et al. (2003), adapted to the logistics industry in Vietnam.

The research model consists of 12 criteria: service quality, customer relationship management, customer retention, human resources, corporate culture, corporate structure, leadership, economics, technology, labor, competitive level are classified into 3 components that make up the success of logistics enterprises, including: factors related to customers, factors of business environment and factors related to the internal issues of enterprise. The research scale is designed and coded based on the Likert scale of 7. However, all businesses are influenced by factors of the business environment, so the factors related to the customer and the internal issues of business are prioritized to be included in the analysis.

The data was analyzed and made official based on the results from fuzzy set analysis using the Truth Table algorithm on the fsQCA software. This software is suitable for medium-sized studies like the authors' ongoing research.

When analyzing in detail the influence of each factor of the two components relating to the customer and internal issues of business relating to the success of the logistics business, the authors obtained the results as Table 3:

Table 3: A combination of factors that affect success of two business groups

\begin{tabular}{|c|c|c|c|}
\hline $\begin{array}{l}\text { Successful groups of } \\
\text { companies }\end{array}$ & Factors & \multicolumn{2}{|c|}{ Other group of companies } \\
\hline ? & Service quality & ? & 回 \\
\hline ? & Customer relations management & ? & ? \\
\hline 回 & Customer retention & ? & \\
\hline ? ? & Human resources & & ?? \\
\hline ?] & Corporate culture & 回 & ?? \\
\hline ?] & Corporate structure & ?] & ?? \\
\hline ? & Leaders' ability & ? & 目 \\
\hline
\end{tabular}

Taking into account the impact of all seven variables on the success of the logistics business in Vietnam, for all successful businesses in the industry, all factors affect the company's business results if they interact with each other and are combined to create a quite large level of influence for each logistics business. For other logistics businesses, their concern is not all of the seven elements. Two different perspectives are given when firms assess the factors that influence success. One view is that there are only six factors: quality of service, customer relationship management, customer retention, corporate culture, corporate structure and leadership are interlinked to influence the performance of a business. Human resources are not an important factor when considering the impact on the business. The other viewpoint is that customer retention has no impact on the business but instead is the human resources that the company has. It is human resources that join the other five factors to resonate with each other in relation to the success that the business wishes to achieve. 


\section{References}

[1] Alan C.Maltz. (2000). Defining and Measuring Organizational Success: A Multi-dimensional Framework. Faculty of the Stevens Institute of Technology.

[2] Emmenegger, Patrick. (2011). Job Security Regulations in Western Democracies: A Fuzzy Set Analysis. European Journal of Political Research 50.

[3] Leischnig, A., Henneberg, S. C., \& Thornton, S. C. ( 2014). Performing Configurational Analyses in Management Research: A Fuzzy Set Approach, (pp. 1-21). Bordeaux.

[4] Ragin, Charles C. (2008). Redesigning social inquiry: Fuzzy sets and beyond. Chicago: University of Chicago Press. 